\title{
The emerging chondrocyte channelome
}

\author{
Richard Barrett-Jolley ${ }^{1}$, Rebecca Lewis', Rebecca Fallman' and Ali Mobasheri ${ }^{2}$ * \\ Musculoskeletal Research Group, Department of Comparative Molecular Medicine, School of Veterinary Science, University of Liverpool, Liverpool, UK \\ ${ }_{2}^{2}$ Musculoskeletal Research Group, Division of Veterinary Medicine, School of Veterinary Medicine and Science, Faculty of Medicine and Health Sciences, University of \\ Nottingham, Nottingham, Leicestershire, UK
}

\section{Edited by:}

Antonio Felipe, Universitat de

Barcelona, Spain

Reviewed by:

Carmen Valenzuela, Instituto de

Investigaciones Biomédicas

CSIC-UAM, Spain

Peter Larsson, University of Miami

School of Medicine, USA

\section{*Correspondence:}

Ali Mobasheri, Faculty of Medicine and Health Sciences, School of Veterinary Medicine and Science, University of Nottingham, Sutton Bonington Campus, Sutton Bonington,

Nottingham, Leicestershire LE12 5RD UK.

e-mail: ali.mobasheri@nottingham. ac.uk
Chondrocytes are the resident cells of articular cartilage and are responsible for synthesizing a range of collagenous and non-collagenous extracellular matrix macromolecules. Whilst chondrocytes exist at low densities in the tissue $(1-10 \%$ of the total tissue volume in mature cartilage) they are extremely active cells and are capable of responding to a range of mechanical and biochemical stimuli. These responses are necessary for the maintenance of viable cartilage and may be compromised in inflammatory diseases such as arthritis. Although chondrocytes are non-excitable cells their plasma membrane contains a rich complement of ion channels. This diverse channelome appears to be as complex as one might expect to find in excitable cells although, in the case of chondrocytes, their functions are far less well understood. The ion channels so far identified in chondrocytes include potassium channels $\left(K_{A T P}, B K, K_{v}\right.$, and SK), sodium channels (epithelial sodium channels, voltage activated sodium channels), transient receptor potential calcium or non-selective cation channels and chloride channels. In this review we describe this emerging channelome and discuss the possible functions of a range of chondrocyte ion channels.

Keywords: chondrocyte, $\mathrm{K}_{\mathrm{v}}$ channel, $\mathrm{K}_{\text {ATP }}$ channel, BK (MaxiK) channel, ENaC

\section{INTRODUCTION}

Chondrocytes are metabolically active cells found in mature articular cartilage (Iannotti, 1990; Archer and Francis-West, 2003). The extracellular matrix (ECM) of cartilage is composed of elastic and collagen fibers (mainly type II collagen), which provide tensile strength with embedded proteoglycans forming a gel-like ground substance that provides elasticity and the ability to resist compressive forces (Buckwalter and Mankin, 1998). Chondrocytes occur singularly or in groups or clusters of three or more cells within spaces called lacunae in the ECM (Stockwell, 1975). Articular cartilage has a high matrix to cell ratio, with chondrocytes occupying only $10 \%$ of the total tissue in mammals (Carney and Muir, 1988). Articular cartilage is a type of hyaline cartilage that covers the surface of bones which meet at a synovial joint (Mankin, 1982). Synovial joints include a cavity between the bones within the articular capsule in order to allow free movement (Edwards et al., 1994). The synovial cavity contains synovial fluid, which acts as a lubricant to decrease friction between the bones meeting

Abbreviations: ASIC, acid sensing ion channel; BK, calcium-activated potassium channel, high conductance; CFTR, cystic fibrosis transmembrane conductance regulator; ClC, chloride channel; DEG, degenerin; ECM, extracellular matrix; ENaC, epithelial sodium channels; IC50, concentration causing 50\% inhibition; $\mathrm{K}_{\mathrm{ATP}}$, ATP dependent potassium channel; $\mathrm{K}_{(\mathrm{Ca})}$, calcium activated potassium channels; Kir, inwardly rectifying potassium channel; $\mathrm{K}_{\mathrm{v}}$, voltage-gated potassium channel; MIP, major intrinsic protein; NMDA, $N$-methyl D-aspartate; PCR, polymerase chain reaction; RMP, resting membrane potential; SERCA, sarco/endoplasmic reticulum $\mathrm{Ca}^{2+}$-ATPase; SITS, 4-acetamido-4'-isothiocyanatostilbene-2,2-disulfonic acid; SK, calcium-activated potassium channel, low conductance; SUR, sulfonylurea receptor; TEA, tetraethylammonium; TRP, transient receptor potential channel; TTX, tetrodotoxin; VGCC, voltage-gated calcium channels; VGSC, voltage-gated sodium channel at the synovial joint and absorbs shock. Friction would be undesirable because it would damage the joint and also generate heat, thereby causing pain (Tatari, 2007). Articular cartilage is avascular without a perichondrium connective tissue surround. In human articular cartilage, chondrocytes may be as far away as $3 \mathrm{~mm}$ from the nearest artery. Therefore, synovial fluid supplies chondrocytes in adult articular cartilage with oxygen and nutrients, and removes carbon dioxide and metabolic waste products, by diffusion (Lee and Urban, 1997; Allan, 1998). Synovial fluid is periodically washed over the surface of the articular cartilage by the movement of the joint (Lee and Urban, 1997). Oxygen and substrate concentrations within cartilage reduce near to the cartilage-bone margin to almost zero (Otte, 1991). Therefore, chondrocytes generate ATP by substrate-level phosphorylation during anaerobic respiration, leading to the accumulation of lactate and lowering of the $\mathrm{pH}$ through the production of $\mathrm{H}^{+}$ions, which can continue in anoxic conditions (Lee and Urban, 1997). The extracellular pH affects the chondrocyte metabolism and its ability to synthesize matrix. Low $\mathrm{pH}$ reduces lactate production, but also slows down the synthesis of glycosaminoglycans. However, the rate of collagen synthesis appears to be independent of pH (Wu et al., 2007). Chondrocytes embedded within the ECM have an unusual ionic environment because they are surrounded by negatively charged proteoglycans, which attract large numbers of cations, such as $\mathrm{Na}^{+}$ions, creating a high extracellular osmolarity and contributing to the low $\mathrm{pH}$ (Urban et al., 1993).

Chondrocyte primary function is to synthesize and secrete proteoglycans, collagen and non-collagenous proteins to maintain the cartilage ECM (Fassbender, 1987). Chondrocytes maintain cartilage by establishing a balance between replacing degraded 
macromolecules and increasing synthesis in response to injury (Martin and Buckwalter, 2000). Proteoglycans contribute to cartilage rigidity, stability and durability during compression (Redini, 2001). Types II, IX, and XI collagen form the tensile fibril networks within cartilage. Type VI collagens form adjacent to chondrocytes and may be involved in attachment of the chondrocyte to the ECM (Bruckner and van der Rest, 1994). Non-collagenous proteins, such as anchorin CII, are also involved in chondrocyte anchorage (Fernandez et al., 1990). The cartilage matrix protects chondrocytes from mechanical stress placed on the joint (Buckwalter and Mankin, 1998; Martin and Buckwalter, 2000). Chondrocyte metabolic activity is directly correlated with the weight of mechanical stress placed on the cartilage; increased activity when the cartilage is heavily loaded provides maximum proteoglycan content (Urban, 1994). The ability of articular cartilage to withstand and respond to pressure and shearing forces is vital for it to fulfill its function. Accumulating evidence suggests that the resting membrane potential (RMP) is vital for fulfilling this function. The RMP has been shown to be central to the secretion and synthesis of substances in a variety of other cell types (Breittmayer et al., 1996; McCarty, 1999; Penyige et al., 2002). It therefore seems likely that if the RMP of chondrocytes is changed by ion channel manipulation, their ability to produce ECM will be compromised. This conjecture is indeed supported by experiments where RMP modifying ion channel blockers reduced the production of matrix mRNAs
(Wu and Chen, 2000), proteins and sulfated glycosaminoglycans (Mouw et al., 2007). Chondrocyte proliferation is also inhibited by channel blockers lidocaine and verapamil (Wohlrab et al., 2001, 2005) and apoptosis increased (Grishko et al., 2010). As with other cells, the chondrocyte RMP is determined by the balance of positive and negative ion permeabilities in the cell membrane (Hodgkin and Huxley, 1952a). These permeabilities are, in turn, controlled by the chondrocyte channelome (the complement of expressed ion channels and porins).

Ion channels are the essential components that control ion movement in and out of the cell (Hodgkin and Huxley, 1952a). They are embedded within the plasma membrane and usually consist of one or more proteins with a central aqueous pore, which opens by conformational change (Neher and Sakmann, 1992). The stimulus for opening (gating) is specific to each ion channel, and may be voltage, chemically or mechanically induced (Hille, 2001). A number of studies have now shown the presence of an ever-expanding list of ion channels in chondrocytes (Figure 1), and this review will summarize the data to date, both on the variety of expression and the proposed roles of these channels.

\section{$\mathrm{K}_{\mathrm{v}}$ CHANNELS}

One of the first discovered ion conductances in biology was the potassium delayed rectifier (Hodgkin and Huxley, 1952b; Ramage et al., 2008). The ion channels underlying this are now known to be

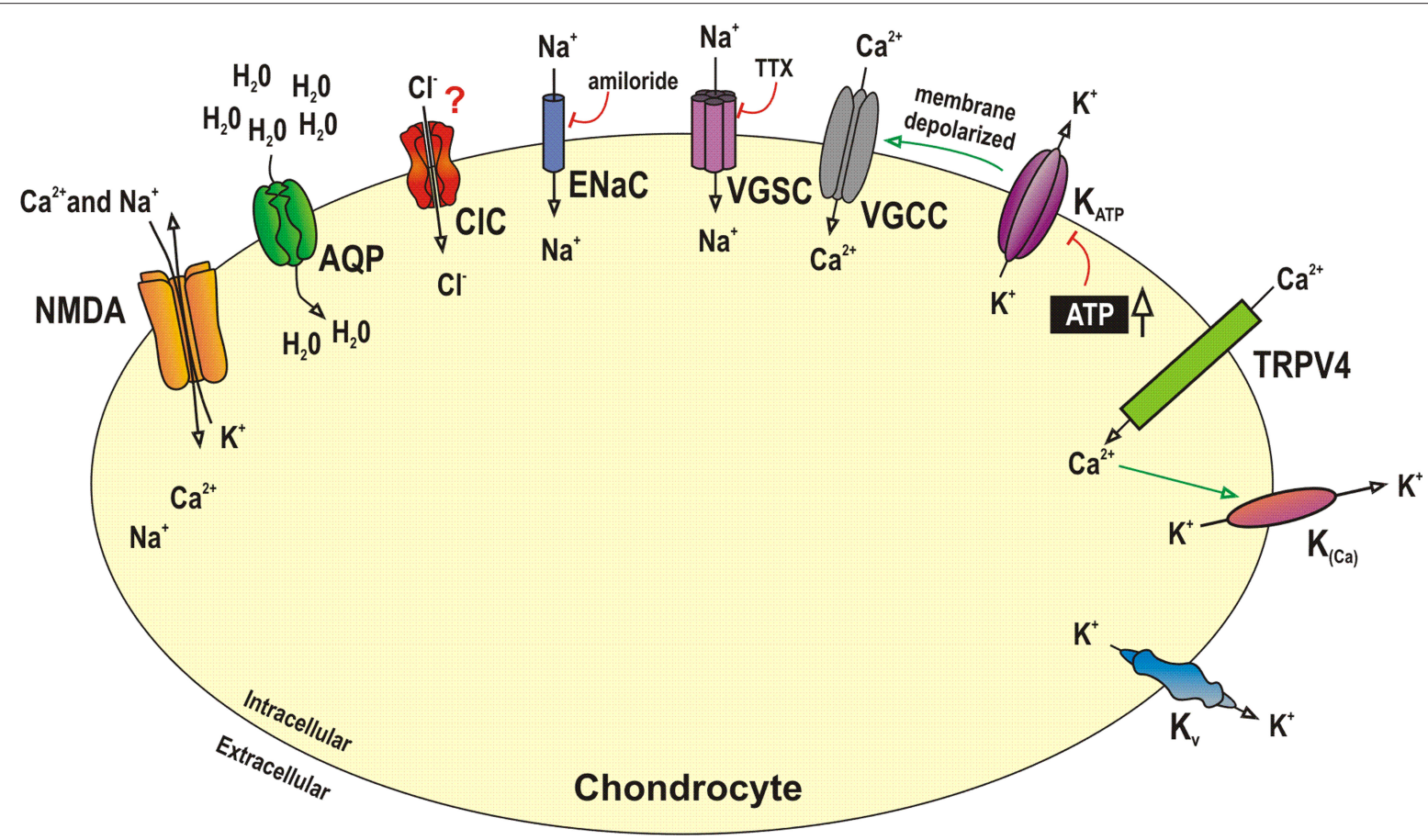

FIGURE 1 | Summary of the chondrocyte channelome. Many studies have now identified ion channels and porins in chondrocytes. Frequently the function of these channels is either unknown or controversial. This figure illustrates some of the major channel proteins identified to date, either by electrophysiological, immunological or molecular biological techniques. Note in this figure, $K_{(\mathrm{Ca})}$ is taken to be equivalent to any calcium activated potassium channel including BK and SK. AQP, aquaporin channel; BK, calcium-activated potassium cannel, high conductance; $\mathrm{CIC}$, chloride channel; ENaC, epithelial sodium channels; $K_{\text {ATP' }}$ ATP dependent potassium channel; Kv, voltage-gated potassium channel; NMDA, N-methyl D-aspartate; SK, calcium-activated potassium channel, low conductance; TRP, transient receptor potential channel; VGCC, voltage-gated calcium channels; VGSC, voltage-gated sodium channel; This data is summarized more fully in Table 1. For references please see text and or Table $\mathbf{1 .}$ 
members of the $\mathrm{K}_{\mathrm{v}}$ potassium channel family. This family is one of the largest ion channel families with at least 40 members (Gutman et al., 2005) of six transmembrane domains. Interestingly these were also one of the earliest ion channels discovered in chondrocytes (Walsh et al., 1992; Sugimoto et al., 1996). K channels have now been reported in chondrocytes by a number of authors and have been shown to be archetypal slowly inactivating ion channels (Walsh et al., 1992; Wilson et al., 2004; Mobasheri et al., 2005a; Ponce, 2006). In essence, these channels are very similar to those channels found in skeletal muscle (Pallotta and Wagoner, 1992) and in neurones (Barrett-Jolley et al., 2000) where, in those cell types, they are critical for repolarization of the membrane following an action potential. The role of a delayed rectifier channel in the chondrocyte plasma membrane is far less clear. Since the chondrocyte exists at far more depolarized levels than neurones or skeletal muscle (Wright et al., 1992; Wilson et al., 2004), logic would suggest that these channels would be constantly inactivated. Close study of the mathematical relationship between voltage, time and fractional inactivation (Hodgkin and Huxley, 1952b) reveals that a certain, albeit small, proportion of these channels will remain active even at the relatively depolarized RMP of a chondrocyte. This is supported by the observation by Wilson et al. (2004) and Clark et al. (2010b) that TEA inhibition of the potassium channels does have a significantly depolarizing effect on chondrocyte RMP, as it does with other non-excitable cells such as those of smooth muscle (Telezhkin et al., 2001; Park et al., 2007).

Relatively few studies have attempted to establish the molecular identity of the delayed rectifier in chondrocytes. However, reports suggest that these channels are similar between species (chicken, canine, equine, and elephant) in terms of their steady-state halfactivation voltage and slope (Wilson et al., 2004; Mobasheri et al., 2005a; Ponce, 2006). Half activation parameters range from 12 to $25 \mathrm{mV}$; typical of $\mathrm{K}_{\mathrm{v}}$ 1. $\mathrm{x}$ or $\mathrm{K}_{\mathrm{v}} 4$.x potassium channels (Coetzee et al., 1999). Activation time constants are, however, quite fast compared with many $\mathrm{K}_{\mathrm{v}}$ channels (Mobasheri et al., 2005a). Such rapid kinetics have been reported for members of the $\mathrm{K}_{\mathrm{v}}$ 1.x family and also homomeric $K_{v} 3.4$ (Coetzee et al., 1999). The inactivation time constant in the order of seconds (Mobasheri et al., 2005a) is typical of $K_{v} 1 . x$, $K_{v}$ 2.x and $K_{v}$ 3.x channels (Coetzee et al., 1999). Together these data suggested that the potassium channel of chondrocytes is likely to be a member of the $\mathrm{K}_{\mathrm{v}}$ 1.x. Pharmacological data are discussed in (Mobasheri et al., 2005a) and are not entirely consistent for $\mathrm{K}_{\mathrm{v}} 1 . \mathrm{x}$ channels or one particular $\mathrm{K}_{\mathrm{v}}$ channel. We therefore feel that the key, published data identifying the subunit identity of the chondrocyte $\mathrm{K}_{\mathrm{v}}$ channels are the immunohistochemical and RT-PCR data. Such data have unequivocally revealed the presence of $\mathrm{K}_{\mathrm{v}} 1.4$ subunits in equine chondrocytes (Mobasheri et al., 2005a) and $\mathrm{K}_{\mathrm{v}} 1.6$ in the mouse (Clark et al., 2010b). Since $\mathrm{K}_{\mathrm{v}}$ channels are known to exist as functional heteromultimers (Villalonga et al., 2010) we would tentatively suggest that articular chondrocytes may express $\mathrm{K}_{\mathrm{v}} 1 . \mathrm{x}$, probably as a heteromultimer including the $\mathrm{K}_{\mathrm{v}} 1.4$ or $\mathrm{K}_{\mathrm{v}} 1.6$ subunits and probably some other, as yet unidentified, $\mathrm{K}_{\mathrm{v}}$ subunit(s).

\section{INWARDLY RECTIFYING POTASSIUM CHANNELS}

Study of inwardly rectifying potassium channels is greatly hampered by a lack of selective inhibitors. Barium and chloroethylclonidine are inhibitors of the strong inward rectifiers (Standen and Stanfield, 1978; Barrett-Jolley et al., 1999) and glibenclamide is an inhibitor of ATP dependent potassium channels (Tomai et al., 1994). So far only $\mathrm{K}_{\text {ATP }}$ channels have been observed in chondrocytes (Mobasheri et al., 2007). $\mathrm{K}_{\text {ATP }}$ channels are a widely expressed subfamily of inwardly rectifying potassium channels. These channels are closed by intracellular ATP and thus serve to couple metabolism to membrane excitability (Quayle et al., 1997; Ashcroft and Gribble, 1998; Minami et al., 2004). Structurally these channels exist as heteromultimers. Each functioning protein consists of four ATP binding cassette proteins (SUR) surrounding four inwardly rectifying potassium channel subunits (Kir 6.x) (Babenko et al., 1998). Of particular interest to investigators of chondrocyte function is the fact that, in addition to being opened by decreasing intracellular ATP (Figure 2), $\mathrm{K}_{\mathrm{ATP}}$ channels are also frequently observed to be opened by low oxygen tension and hypoxia (Dart and Standen, 1994). This suggests that these channels are important in hypoxia-mediated cell signaling (Phillis, 2004). We showed recently that $\mathrm{K}_{\mathrm{ATP}}$ channels were expressed in articular chondrocytes (Mobasheri et al., 2007). We used polyclonal antibodies raised against the $\mathrm{K}_{\text {ATP }}$ channel to show expression in both human and equine chondrocytes. Expression was largely restricted to the superficial and middle zones of normal cartilage and the superficial zone of fibrillated osteoarthritic cartilage in clusters (Mobasheri et al., 2007). In patch-clamp studies we found the biophysical properties of $\mathrm{K}_{\text {ATP }}$ channels to be broadly similar to $\mathrm{K}_{\text {ATP }}$ channels expressed elsewhere (Babenko et al., 1998; Mobasheri et al., 2007). Several $K_{\text {ATP }}$ subtypes (i.e., Kir 6.1 and Kir 6.2) are each potentially coupled with one of the SUR subtypes; SUR1, 2A or 2B (Babenko et al., 1998). Pharmacological properties of $\mathrm{K}_{\text {ATP }}$ channels are thus very different between tissues. Glibenclamide is sometimes used as a functional discriminator between $\mathrm{K}_{\mathrm{ATP}}$ subtypes. It is highly active in pancreatic $\beta$-cells (IC50 of $<10 \mathrm{nM}$, Krause et al., 1995), but rather less potent in muscle (IC50 25-100 nM, Beech et al., 1993; Barrett-Jolley and Davies, 1997; Barrett-Jolley and McPherson, 1998). In pharmacological studies of chondrocytes, the $\mathrm{K}_{\text {ATP }}$ channel's IC50 is within the range seen in muscle (Mobasheri et al., 2007). It therefore seems highly likely that chondrocytes express at least one subtype of $\mathrm{K}_{\mathrm{ATP}}$ channel and that these may be important for regulation of cartilage metabolism and sensing ATP levels within the cell (Mobasheri et al., 2005b).

\section{LARGE CALCIUM-ACTIVATED POTASSIUM CHANNELS}

Several studies have putatively identified BK channels in chondrocytes (Grandolfo et al., 1990, 1992; Long and Walsh, 1994; Martina et al., 1997; Mozrzymas et al., 1997; Mobasheri et al., 2010). In our own study (Mobasheri et al., 2010), the principal stretch-activated channel we identified had a slope conductance, reversal potential, and pharmacology consistent with it being a large calcium-activated potassium channel (BK) (Latorre et al., 1989; Cui et al., 2009). We found the sensitivity to iberiotoxin to be statistically significant but weak (Mobasheri et al., 2010). This is interesting because whilst the BK channel can exist as a standalone six trans-membrane $\alpha$-subunit, complete with potassium conducting pore and $\mathrm{Ca}^{2+}$ sensor (Wang and Sigworth, 2009), the presence or absence of a $\beta$-subunit determines many of the channel's functional properties (Salkoff et al., 2006; Torres et al., 2007). In particular, low sensitivity to iberiotoxin is highly characteristic of the expression of 


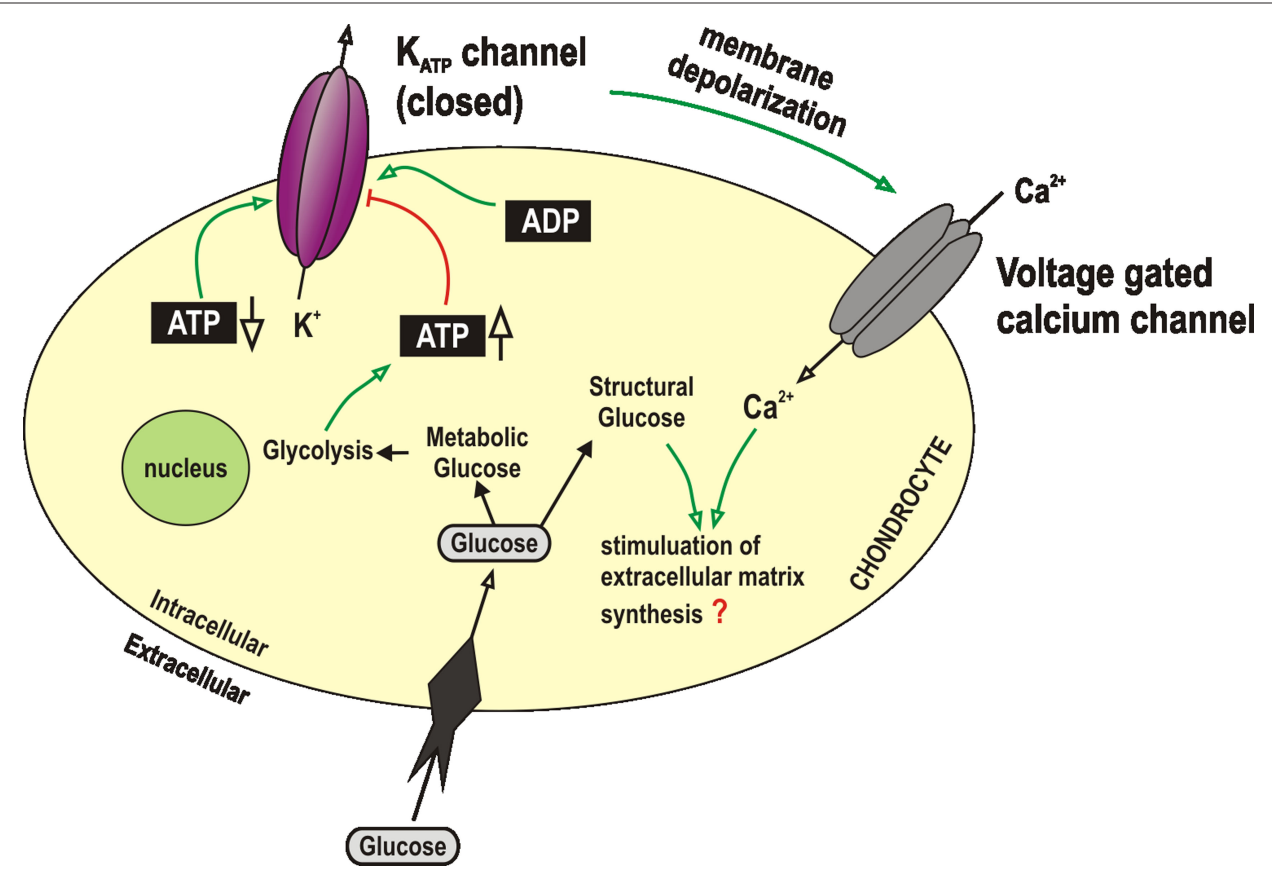

FIGURE 2 | $\mathbf{K}_{\text {ATP }}$ channels in chondrocytes. Chondrocytes have been shown to express $K_{\text {ATP }}$ channels. The function of these is generally accepted to be coupling metabolic status with membrane potential and thus cell activity. In other cell types, endogenous triggers for activation of $\mathrm{K}_{\text {ATP }}$ include decrease of intracellular
ATP (Babenko et al., 1998), increase in ADP (Dunne and Petersen, 1986), extracellular hypoxia (Dart and Standen, 1994) or other chemical signals such as adenosine (Dart and Standen, 1993; Barrett-Jolley et al., 1996), angiotensin (Sampson et al., 2007) etc., $K_{\text {ATP, }}$ ATP dependent potassium channel.
BK channels consisting of both the $\alpha 1$ and $\beta 1$-subunits (Lippiat et al., 2003). This correlated well with our identification of positive immunohistochemical staining of normal articular cartilage samples with antibodies to both $\alpha 1$ and $\beta 1$-subunits.

In general terms, there appear to be two possibilities to explain the activation of BK channels by stretch. These could be termed either calcium dependent or calcium independent mechanisms. The calcium dependent hypothesis would require that stretch led to an increase in intracellular $\mathrm{Ca}^{2+}$ and that this activated the $\mathrm{BK}$ channel (Figure 3). Indeed a number of studies show changes in intracellular $\mathrm{Ca}^{2+}$ with osmotic or other mechanical challenge (Grandolfo et al., 1998; Guilak et al., 1999; Yellowley et al., 2002; Sanchez et al., 2003; Sanchez and Wilkins, 2004). The source of such $\mathrm{Ca}^{2+}$ is controversial, but potentially, dogma states that it must come from either influx (e.g., a channel or other transporter protein Sanchez et al., 2003; Sanchez and Wilkins, 2004; Phan et al., 2009) or from intracellular stores (e.g., Grandolfo et al., 1998). The calcium independent hypothesis would involve either direct sensing of stretch by the channel itself, or coupling of the channel to other mechanoreceptors such as integrins (Mobasheri et al., 2002). The function of BK activation by stretch is still unknown, but there are a few clear possibilities. Firstly, the BK channel could be acting as an "osmolyte" channel (Hall et al., 1996; Kerrigan and Hall, 2008), since activation of potassium conductances will allow potassium ions to leave, decrease intracellular osmotic potential and facilitate regulatory volume decrease. Secondly, it is possible that it is the influence of the BK channel on the membrane potential which is critical, as it is in vascular tissue (Ledoux et al., 2006).

\section{SMALL CALCIUM-ACTIVATED POTASSIUM CHANNELS}

In addition to the body of work showing the presence of BK channels, there have also been a few reports of SK activity in chondrocytes (Wright et al., 1996; Lee et al., 2000; Ramage et al., 2008; Funabashi et al., 2010b). In the study by Wright et al. (1996), osmotic shock led to a hyperpolarization, which was largely insensitive to iberiotoxin, but highly sensitive to the SK channel inhibitor, apamin. Interestingly, in our own study of stretch activated potassium channels in chondrocytes (Mobasheri et al., 2010), whilst single channel studies clearly identified BK channels, the hypo-osmotic hyperpolarization was resistant to the low concentrations of TEA which would be expected to block BK channels. The hyperpolarization was, however, inhibited by symmetrical $10 \mathrm{mM}$ TEA. This was an observation consistent with the original observations of an SK component to the hyperpolarization shown by Wright et al. (1996), since both SK and BK are rather resistant to extracellular TEA (Latorre et al., 1989).

\section{TRANSIENT RECEPTOR POTENTIAL CHANNELS}

Transient receptor potential (TRP) channels are a family of loosely related ion channels that show relatively little selectivity between permeable cations such as sodium, calcium, and magnesium ${ }^{1}$. They were initially proposed to couple hypo-osmotic shock to intracellular $\mathrm{Ca}^{2+}$ mobilization in chondrocytes on the basis of gadolinium sensitivity (Sanchez et al., 2003), but since then several

\footnotetext{
${ }^{1}$ Transient receptor potential channels. Authors: David E. Clapham, Bernd Nilius, Grzegorz Owsianik. Last modified on 2010-04-07. Accessed on 2010-06-24. IUPHAR database (IUPHAR-DB), http://www.iuphar-db.org/DATABASE/Family MenuForward?familyId=78.
} 


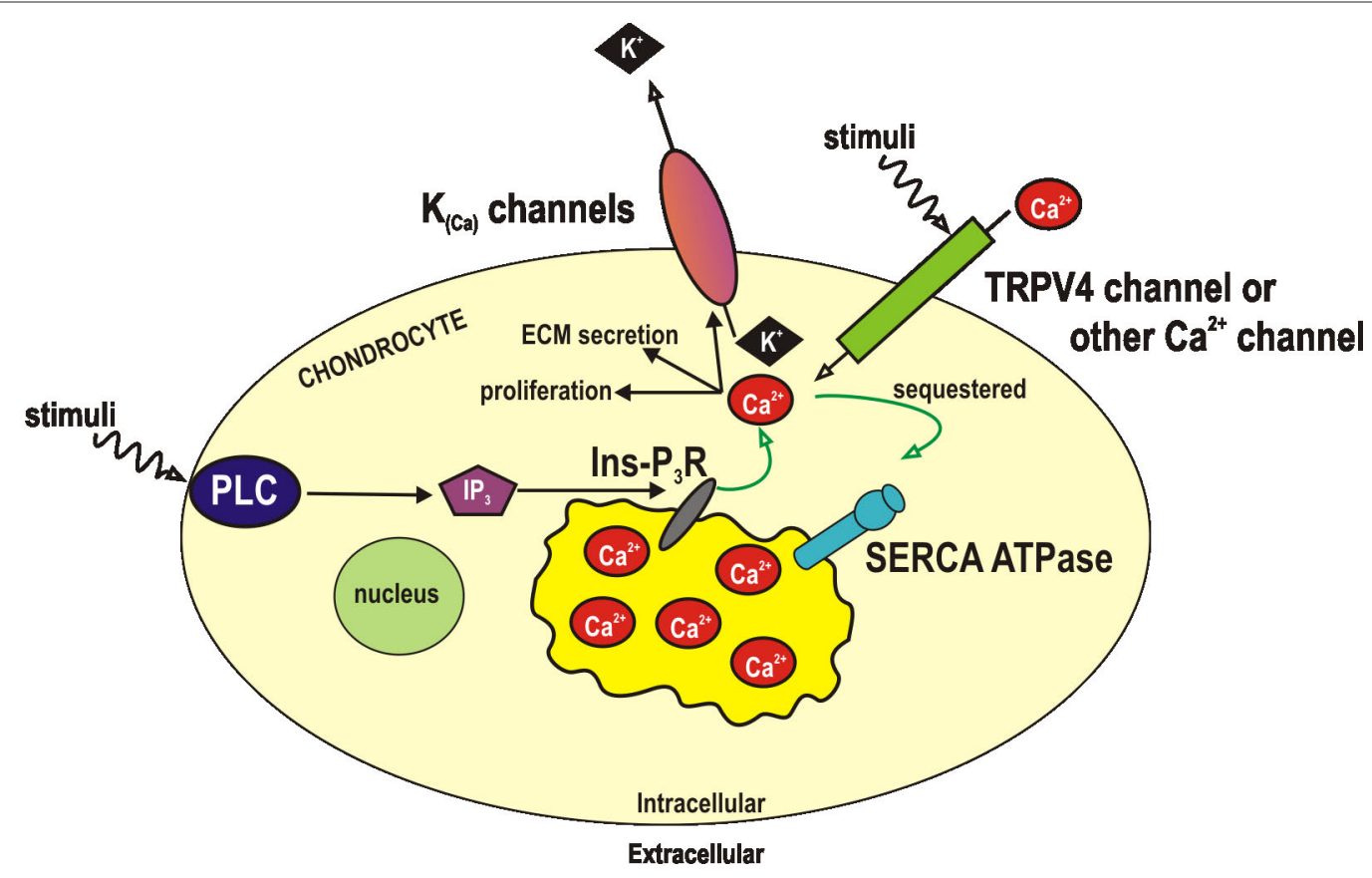

FIGURE 3 |Activation of BK by calcium ions. A number of studies have identified BK channels in chondrocytes (see text), but the function of these channels is not confirmed. Control of RMP or volume would are two theories. It is suggested that they are activated by calcium ions, which could be introduced to the cytoplasm by either release from stores, or by entry through divalent cation permeant ion channels. Both of these pathways could in turn, be activated by either mechanical or other (e.g., inflammatory) signals. ECM, extracellular matrix; Ins-P3-R, inositol trisphosphate receptor; IP3, inositol trisphosphate; $\mathrm{K}_{(\mathrm{Ca})^{\prime}}$ calcium activated potassium channels; PLC, phospholipase C; SERCA, sarco/ endoplasmic reticulum $\mathrm{Ca} 2+\mathrm{ATPase}$; TRP, transient receptor potential channel.
TRP channels have been identified in osteoarthritic cartilage by PCR (Gavenis et al., 2009). TRPV4 has also been identified in both porcine and canine chondrocytes (Phan et al., 2009; Lewis et al., 2010) by PCR. TRPV4 is an established stretch activated channel and is widely regarded to be a conduit for stretch-activated entry of calcium ions (Nilius et al., 2004). TRPV4 has been shown to be a regulator of the chondrogenic SOX9 pathway (Muramatsu et al., 2007) and the deficiency of TRPV4 in knockout mice leads to a loss of $\mathrm{Ca}^{2+}$ response to hypo-osmotic challenge and the onset of osteoarthritic changes (Clark et al., 2010a). Thus, it may be that by linking chondrocyte membrane stretch to calcium mobilization TRPV4 is key to regulation of chondrogenesis, activation of calcium activated potassium channels and volume regulation.

\section{VOLTAGE-GATED CALCIUM CHANNELS}

Voltage-gated calcium channels (VGCC) are a group of calcium permeable voltage-gated ion channels found in excitable cells (e.g., muscle, glial cells, neurones, etc., Goldin, 2001; Dolphin, 2009). The presence of L-type VGCCs was suggested by Wright et al. (1996) on the basis of pharmacological inhibition of calcium dependent hyperpolarization by somatostatin and cadmium. It should be noted that whilst this is a plausible hypothesis, both somatostatin and cadmium affect a range of other ion channels including transient receptor potential channels (Carlton et al., 2004; Alexander et al., 2008), which may be present in chondrocytes. Ultrastructural studies have confirmed the presence of L-type VGCCs in mouse limb bud chondrocytes (Shakibaei and Mobasheri, 2003). These channels appear to be organized around $\beta$ - 1 integrin receptors with kinases and cytoskeletal complexes in close proximity. The presence of L-type (and T-type) calcium channels in chondrocytes was recently supported by Mancilla et al. (2007), however, (Sanchez and Wilkins, 2004) found that osmotically induced changes in intracellular calcium ions were not influenced by more selective L-type calcium channel blockers (including verapamil). In contrast aggrecan and collagen synthesis induced by electrical stimulation of cartilage is dependent upon the activity of VGCCs (Xu et al., 2009). Clearly, further evidence for the presence of this channel is needed to clarify these data.

\section{VOLTAGE-GATED SODIUM CHANNELS (VGSC)}

Voltage-gated sodium channels (VGSC) are integral membrane proteins that are activated in response to voltage-changes across the plasma membrane (Catterall, 1991, 1992, 1995, 2002). The presence of tetrodotoxin sensitive VGSC in rabbit chondrocytes has been reported by Sugimoto et al. (1996) and in chondrocytes from osteoarthritic cartilage by Ramage et al. (2008). It would be interesting to see how the expression of this channel fits into the control of the chondrocyte membrane potential, since current studies have failed to observe sufficient hyperpolarization of chondrocytes for a typical VGSC to be substantially reactivated. Under conditions of constant depolarization, for example, these channels would be permanently inactivated.

\section{EPITHELIAL SODIUM CHANNELS}

Epithelial sodium channels $(\mathrm{ENaC})$ have been identified in chondrocytes both immunohistochemically (Trujillo et al., 1999) and functionally (Lewis et al., 2008). They are members of the 
degenerin (DEG) and ENaC superfamily (Mano et al., 2009). ENaC is a heteromeric channel, formed of up to four subunits; $\alpha, \beta, \delta$, and $\gamma$ (Canessa et al., 1994). Using immunohistochemistry, the $\alpha$ and $\beta$ subunits have been shown to be present in chondrocytes (Trujillo et al., 1999). ENaCs are significantly more permeable to sodium than potassium (Eaton et al., 1995) and are sensitive to the channel inhibitor amiloride (IC50 100-200 nM; Alexander et al., 2008). The $\mathrm{ENaCs}$ main function in the kidney, bladder, and colon is control of sodium reabsorption (Rossier et al., 2002). They are found in lung tissue (Mall et al., 1998) and the taste buds (Lindemann, 2001) and are known to regulate blood volume and pressure through sodium balance in the cardiac system (Canessa et al., 1993). ENaC is known to have roles in various disease states, including cystic fibrosis and Liddle's Syndrome (Snyder et al., 1995; Stutts et al., 1995). Differential expression and up-regulation of the subunits between normal and disease states is thought to contribute to cellular changes in disease (Burch et al., 1995; Greig et al., 2004). In chondrocytes the role of $\mathrm{ENaC}$ is less clear; however, it is thought to be one of mechanotransduction, possibly where the channel contributes to the maintenance of the RMP. This, in turn, may regulate signaling pathways that allow chondrocytes to maintain their ECM and prevent chondrocyte apoptosis (Wright et al., 1996; Shakibaei et al., 2001; Shakibaei and Mobasheri, 2003). It is thought that the mechanotransduction pathways involving $\mathrm{ENaC}$ become progressively defective during osteoarthritis, leading to a loss of chondroprotective mechanisms (Salter et al., 2004). It is possible that $\mathrm{ENaC}$ subunits are differentially expressed in chondrocytes, potentially to cope with different mechanical stresses throughout the zones of articular cartilage, and changes in chondrocytic properties during disease (Trujillo et al., 1999; Shakibaei et al., 2001).

\section{CHLORIDE CHANNELS}

The chloride channel family $(\mathrm{ClC})$ is widely expressed in many tissue types. It was first discovered by Jentsch et al. (1990) using Xenopus oocytes, who isolated and sequenced the channel primary structure using cDNA. Using the same $\mathrm{CDNA}, \mathrm{ClC}-1$ was identified in rat skeletal muscle. In skeletal muscle, $\mathrm{ClC}-1$ is involved in stabilization of the RMP (Gronemeier et al., 1994). ClCs have been identified in rabbit articular cartilage (Sugimoto et al., 1996; Tsuga et al., 2002; Isoya et al., 2009) and in OUMS-27, the human chondrocyte-derived cell line (Funabashi et al., 2010a). A commonly used pharmacological inhibitor of $\mathrm{ClCs}$ is 4 -acetamido-4' ${ }^{\prime}$-isothiocyanatostilbene-2,2disulfonic acid (SITS) (Pesente and Signorile, 1979; Lefevre et al., 1996; Vaca, 1999; Alexander et al., 2008). This and other ClC inhibitors were used by Sugimoto et al. (1996) and Tsuga et al. (2002) to show that ClCs are important for control of the RMP. Furthermore, exposure of chondrocytes to high concentrations of SITS leads to signs of necrotic damage (Wohlrab et al., 2004) suggesting that activity of ClCs may be critical to the survival of chondrocytes. Chondrocytes may express a number of ClCs. So far the only one successfully identified in molecular terms is the cystic fibrosis transmembrane conductance regulator (CFTR) (Liang et al., 2010). This is particularly interesting since CFTR is known to function both as a channel in its own right, and as a regulator of other ion channels known to be expressed in chondrocytes (Mall et al., 1998; Nilius and Droogmans, 2003; Arniges et al., 2004). As yet no studies have successfully identified other ClCs expressed by chondrocytes. Such identification will be a tricky task since the $\mathrm{ClC}$ family is large and the available pharmacological inhibitors are rather non-selective between each of the family members (Alexander et al., 2008). In our own laboratories we have attempted to locate $\mathrm{ClC}-1 \mathrm{mRNA}$ using the primers based on the sequence already identified for canine skeletal muscle (Rhodes et al., 1999). These studies show a lack of ClC-1, but as yet there have been no positive studies on chondrocytes. The identity was suggested to be the maxi-ClC by Yabu and colleagues (Sugimoto et al., 1996; Tsuga et al., 2002), but further studies will be needed to clarify this. The ClC identified in rabbit articular cartilage by Isoya et al. (2009) proved to be swelling activated, but whilst its molecular identity is unknown, $\mathrm{ClC}-3$ was suggested as a possibility on the basis of its biophysical and pharmacological properties. In terms of the function of ClCs in chondrocytes, at least two clear possibilities exist; the first would be that they are required for setting of the membrane potential as implied above, but the second would be that they could be important as anionic osmolyte channels. The latter hypothesis arises from the fact that any osmotic loss of $\mathrm{K}^{+}$ions as a part of volume regulation would need to be matched by an effective anion loss. ClCs would be an obvious candidate to fulfill such a role.

\section{AQUAPORIN CHANNELS}

Aquaporins (AQP) are a family of small integral membrane proteins related to the major intrinsic protein (MIP), sometimes called AQP0 (Agre et al., 1993). The first AQP discovered, AQP1, was identified during experiments investigating the identity of the rhesus blood group antigens (Agre et al., 1987; Denker et al., 1988; Smith and Agre, 1991). Oocytes from Xenopus laevis microinjected with in vitro-transcribed mRNA of AQP1 (previously known as CHIP28) exhibited increased osmotic water permeability compared to uninjected controls. This observation, combined with the reversible inhibition induced by mercuric chloride, provided the first molecular evidence for water channels (Preston et al., 1992). Since the identification of AQP1 the field has expanded to now include study of AQP in all types of organisms. In mammals, over a dozen AQP have been identified. The classical AQP transport water exclusively. However, a second class of AQP has now been identified (Rojek et al., 2008), these so-called aquaglyceroporins also transport small, uncharged molecules such as glycerol and urea; examples include AQP3, AQP7, and AQP9 (Carbrey and Agre, 2009). Many models of chondrocyte function involve changes in volume (Hall et al., 1996). For this to occur there must be pathways for the movement of water into and out of the cell. The discovery of AQP channels in chondrocytes would appear to provide an appropriate mechanism (Mobasheri and Marples, 2004; Mobasheri et al., 2004a,b; Trujillo et al., 2004; May et al., 2007). Whilst studies have already shown a loss of volume regulation with inhibition of AQP channels (May et al., 2007) and reductions in migration and adhesion (Liang et al., 2008), it would be interesting to investigate whether cell survival or progression of osteoarthritis are also affected by AQP block or by AQP knockouts.

\section{NMDA CHANNELS}

There have been a few reports of expression of excitatory neurotransmitter receptor (NMDA) channels in chondrocytes (MillwardSadler et al., 2001; Salter et al., 2004; Ramage et al., 2008). These are 


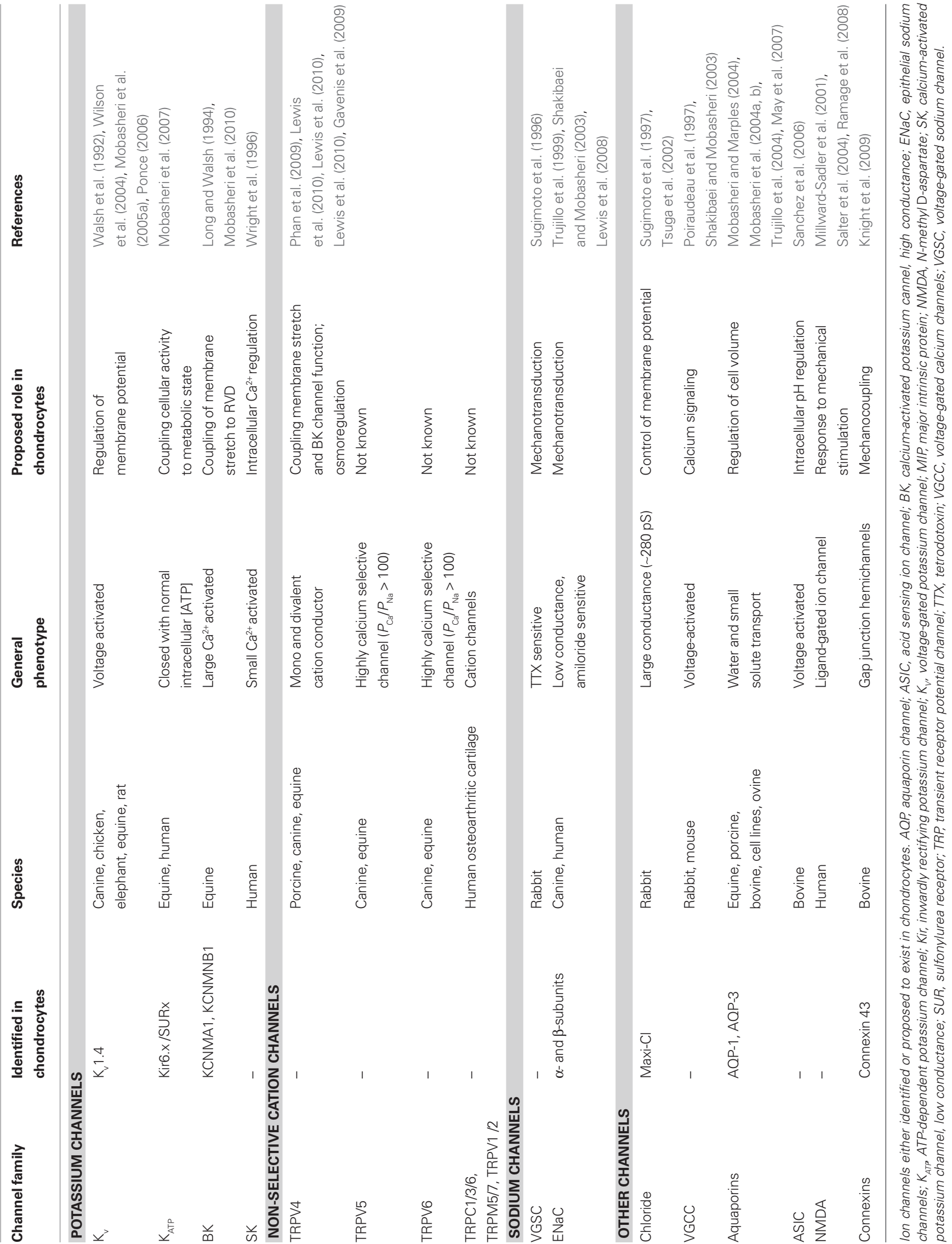


interesting observations however the role of these ligand-gated ion channels in chondrocyte function is not yet understood. It does not seem likely that they are involved with neurotransmission because, despite some similarities between neurone and chondrocyte phenotype, no "pre-synaptic" neurones project to the immediate vicinity of the chondrocytes. It again appears likely that NMDA channels are in someway involved in the mechanotransduction pathway, since mechanically induced hyperpolarizations are reduced by NMDA antagonists (Salter et al., 2004). Furthermore, glycine induces a number of changes on chondrocytes in cartilage explants (including accumulation of calcium) and these effects can be reduced with an NMDA antagonist as, presumably, glycine acts via the glycine binding site of the NMDA receptor (Takahata et al., 2008).

\section{OTHER ION CHANNELS}

Two further ion channels recently identified in chondrocytes are the acid sensing channel, ASIC1a and ASIC3 (Kolker et al., 2010; Yuan et al., 2010) and the connexin 43 hemichannel (Knight et al., 2009). ASIC are very small cation selective channels closely related to $\mathrm{ENaC}$ (reviewed by Wemmie et al., 2006). As their name implies, they are opened by extracellular protons. This is particularly relevant to chondrocyte biology since chondrocytes are routinely exposed to relatively acidic conditions, as low as $\mathrm{pH} 6.6$ for example (Wilkins et al., 2000). In vitro studies show that these channels mediate an increase in intracellular calcium upon exposure of chondrocytes to acidic conditions. This intracellular $\mathrm{Ca}^{2+}$ is likely to be a signal for production of enzymes and for proliferation. Potentially, inappropriate increases in calcium could result in cell death from either necrosis or apoptosis (Kolker et al., 2010; Yuan et al., 2010). The role of the connexin 43 is possibly more complex. Knight et al. (2009) found it to be constitutively active in about $40 \%$ of chondrocytes, and as such it might be expected to profoundly depolarize the membrane. In summary, the suggested scheme of connexin 43 involve-

\section{REFERENCES}

Agre, P., Preston, G. M., Smith, B. L., Jung, J. S., Raina, S., Moon, C., Guggino, W. B., and Nielsen, S. (1993). Aquaporin CHIP: the archetypal molecular water channel. Am. J. Physiol. 265, F463-F476.

Agre, P., Saboori, A. M., Asimos, A., and Smith, B. L. (1987). Purification and partial characterization of the Mr 30,000 integral membrane protein associated with the erythrocyte Rh(D) antigen. J. Biol. Chem. 262, 17497-17503.

Alexander, S. P.H., Mathie, A., and Peters, J. A. (2008). Guide to receptors and channels (GRAC), 3rd edition. Br. J. Pharmacol. 153(Suppl. 2), S1-S209.

Allan, D.A. (1998). Structure and physiology of joints and their relationship to repetitive strain injuries. Clin. Orthop. Relat. Res. 351, 32-38.

Archer, C.W., and Francis-West, P. (2003). The chondrocyte. Int. J. Biochem. Cell Biol. 35, 401-404.

Arniges, M., Vazquez, E., FernandezFernandez, J. M., and Valverde, M.
A. (2004). Swelling-activated Ca2+ entry via TRPV4 channel is defective in cystic fibrosis airway epithelia. $J$. Biol. Chem. 279, 54062-54068.

Ashcroft, F. M., and Gribble, F. M. (1998). ATP-sensitive $\mathrm{K}+$ channels. Trends Neurosci. 21, 288-294.

Babenko, A. P., Aguilar-Bryan, L., and Bryan, J. (1998). A view of sur/KIR6.X, KATP channels. Annu. Rev. Physiol. 60, 667-687.

Barrett-Jolley, R., Comtois, A., Davies, N. W., Stanfield, P. R., and Standen, N. B. (1996). Effect of adenosine and intracellular GTP on K-ATP channels of mammalian skeletal muscle. J. Membr. Biol. 152, 111-116.

Barrett-Jolley, R., Dart, C., and Standen, N. B. (1999). Direct block of native and cloned (Kir2.1) inward rectifier $\mathrm{K}+$ channels by chloroethylclonidine. Br. J. Pharmacol. 128, 760-766.

Barrett-Jolley, R., and Davies, N.W. (1997). Kinetic analysis of the inhibitory effect of glibenclamide on KATP channels of Correlating structure and function in

ment was that mechanical stimulation of chondrocyte cilia activates the hemichannel which then acts as a conduit for ATP release. This released ATP then acts on chondrocyte membranes (via P2 purinoceptors) to increase intracellular $\mathrm{Ca}^{2+}$ (Knight et al., 2009).

\section{CONCLUSIONS}

There is growing interest in the expression and function of ion channels in chondrocytes. Part of this interest stems from the realization that many ion channels are involved in mechanotransduction, chemotransduction and osmoregulation. It is important to bear in mind that ion channels are also important drug targets because of their localization in the chondrocyte plasma membrane. A number of research groups, including ours, have used electrophysiology, molecular biology and immunohistochemistry to study ion channels in articular chondrocytes. Table 1 contains a summary of the ion channels studied in the chondrocyte channelome so far. It is likely that some ion channels in chondrocytes are multifunctional, serving a number of different physiological purposes. The processes of mechanical and chemical sensing and metabolic regulation may well be intricately linked and make use of a number of ion channels as common denominators. In summary, ion channels are important for chondrocyte function and further investigations are required to explore the full complement of channels present in the chondrocyte channelome. This knowledge will help us understand the unique biology of chondrocytes and may lead to the development and formulation of therapeutic strategies to treat arthritis.

\section{ACKNOWLEDGMENTS}

The Biotechnology and Biological Sciences Research Council (BBSRC) and The Wellcome Trust have funded our research on the chondrocyte channelome. We thank Dr Madura Batuwangala for the illustrations in the figures.

mammalian skeletal muscle. J.Membr. Biol. 155, 257-262.

Barrett-Jolley, R., and McPherson, G. A. (1998). Characterization, of K(ATP) channels in intact mammalian skeletal muscle fibres. Br. J. Pharmacol. 123, 1103-1110.

Barrett-Jolley, R., Pyner, S., and Coote, J. H. (2000). Measurement of voltagegated potassium currents in identified spinally-projecting sympathetic neurones of the paraventricular nucleus.J. Neurosci. Methods 102, 25-33.

Beech, D. J., Zhang, H., Nakao, K., and Bolton, T. B. (1993). K channel activation by nucleotide diphosphates and its inhibition by glibenclamide in vascular smooth muscle cells. $\mathrm{Br}$. J. Pharmacol. 110, 573-582.

Breittmayer, J. P., Pelassy, C., and Aussel, C. (1996). Effect of membrane potential on phosphatidylserine synthesis and calcium movements in control and CD3-activated Jurkat T cells. J. Lipid Mediat. Cell Signal. 13, 151-161.

Bruckner, P., and van der Rest, M. (1994). Structure and function of cartilage collagens. Microsc. Res. Tech. 28, 378-384.

Buckwalter, J.A., and Mankin, H. J. (1998). Articular cartilage: tissue design and chondrocyte-matrix interactions. Instr. Course Lect. 47, 477-486.

Burch, L. H., Talbot, C. R., Knowles, M. R., Canessa, C. M., Rossier, B. C., and Boucher, R. C. (1995). Relative expression of the human epithelial $\mathrm{Na}+$ channel subunits in normal and cystic fibrosis airways. Am. J. Physiol. 269, C511-518.

Canessa, C. M., Schild, L., Buell, G., Thorens, B., Gautschi, I., Horisberger, J. D., and Rossier, B. C. (1994). Amiloride-sensitive epithelial $\mathrm{Na}^{+}$ channel is made of 3 homologous subunits. Nature 367, 463-467.

Carbrey, J. M., and Agre, P. (2009). Discovery of the aquaporins and development of the field. Handb. Exp. Pharmacol., 190, 3-28.

Carlton, S. M., Zhou, S., Du, J., Hargett, G. L., Ji, G., and Coggeshall, R. E. (2004). Somatostatin modulates the transient receptor potential vanilloid 
1 (TRPV1) ion channel. Pain 110, 616-627.

Carney, S. L., and Muir, H. (1988). The structure and function of cartilage proteoglycans. Physiol. Rev. 68, 858-910.

Catterall, W. A. (1991). Structure and function of voltage-gated sodium and calcium channels. Curr. Opin. Neurobiol. 1, 5-13.

Catterall, W. A. (1992). Cellular and molecular biology of voltage-gated sodium channels. Physiol. Rev. 72, S15-S48.

Catterall, W. A. (1995). Structure and function of voltage-gated ion channels. Annu. Rev. Biochem. 64, 493-531.

Catterall, W. A. (2002). Molecular mechanisms of gating and drug block of sodium channels. Novartis Found Symp. 241, 206-218; discussion 218-232.

Clark, A. L., Votta, B. J., Kumar, S., Liedtke, W., and Guilak, F. (2010a). chondroprotective role of the osmoticallysensitive ion channel TRPV4: age- and sex-dependent progression of osteoarthritis in Trpv4 deficient mice. Arthritis Rheum.doi: 10.1002/art.27624. [Epub ahead of print].

Clark, R. B., Hatano, N., Kondo, C., Belke, D. D., Brown, B. S., Kumar, S., Votta, B. J., and Giles, W. R. (2010b). Voltagegated $\mathrm{K}^{+}$currents in mouse articular chondrocytes regulate membrane potential. Channels 4, 179-191.

Coetzee, W.A., Amarillo, Y., Chiu, J., Chow, A., Lau, D., McCormack, T., Moreno, H., Nadal, M. S., Ozaita, A., Pountney, D., Saganich, M., Vega-Saenz de Miera, E., and Rudy, B. (1999). Molecular diversity of $\mathrm{K}^{+}$channels. Ann. NY Acad. Sci. 868, 233-285.

Cui, J., Yang, H., and Lee, U. S. (2009). Molecular mechanisms of BK channel activation. Cell. Mol. Life Sci. 66, 852-875.

Dart, C., and Standen, N. B. (1993). Adenosine-activated potassium current in smooth-muscle cells isolated from the pig coronary-artery. $J$. Physiol. (Lond.) 471, 767-786.

Dart, C., and Standen, N. B. (1994). Hypoxia induces a potassium current in smooth-muscle cells isolated from the porcine coronary-artery. J. Physiol. (Lond.) 477P, P85-P86.

Denker, B. M., Smith, B. L., Kuhajda, F. P., and Agre, P. (1988). Identification, purification, and partial characterization of a novel Mr 28,000 integral membrane protein from erythrocytes and renal tubules. J. Biol. Chem. 263, 15634-15642.

Dolphin, A. C. (2009). Calcium channel diversity: multiple roles of calcium channel subunits. Curr. Opin. Neurobiol. 19, 237-244.
Dunne, M. J., and Petersen, O. H. (1986). Intracellular ADP activates $\mathrm{K}^{+}$channels that are inhibited by ATP in an insulin-secreting cell-line. FEBS Lett. 208, 59-62.

Eaton, D. C., Becchetti, A., Ma, H. P., and Ling, B. N. (1995). Renal sodiumchannels - regulation and singlechannel properties. Kidney Int. 48, 941-949.

Edwards, J. C., Wilkinson, L. S., Jones, H. M., Soothill, P., Henderson, K. J., Worrall, J. G., and Pitsillides, A. A. (1994). The formation of human synovial joint cavities: a possible role for hyaluronan and CD44 in altered interzone cohesion. J. Anat. 185(Pt 2), 355-367.

Fassbender,H.G. (1987). Role of chondrocytes in the development of osteoarthritis. Am. J. Med. 83, 17-24.

Fernandez, M. P., Selmin, O., Martin, G. R., Yamada, Y., Pfaffle, M., Deutzmann, R., Mollenhauer, J., and von der Mark, K. (1990). The structure of anchorin CII, a collagen binding protein isolated from chondrocyte membrane. J. Biol. Chem. 265, 8344.

Funabashi, K., Fujii, M., Yamamura, H., Ohya, S., and Imaizumi, Y. (2010a). Contribution of chloride channel conductance to the regulation of resting membrane potential in chondrocytes. J. Pharmacol. Sci. 113, 94-99.

Funabashi, K., Ohya, S., Yamamura, H., Hatano, N., Muraki, K., Giles, W., and Imaizumi, Y. (2010b). Accelerated Ca2+ entry by membrane hyperpolarization due to $\mathrm{Ca}^{+}$-activated $\mathrm{K}^{+}$ channel activation in response to histamine in chondrocytes. Am. J. Physiol. Cell Physiol. 298, C786-C797.

Gavenis, K., Schumacher, C., Schneider, U., Eisfeld, J., Mollenhauer, J., and Schmidt-Rohlfing, B. (2009). Expression of ion channels of the TRP family in articular chondrocytes from osteoarthritic patients: changes between native and in vitro propagated chondrocytes. Mol. Cell. Biochem. 321, 135-143.

Goldin, A. L. (2001). Resurgence of sodium channel research. Annu. Rev. Physiol. 63, 871-894.

Grandolfo, M., Calabrese, A., and D'Andrea, P. (1998). Mechanism of mechanically induced intercellular calcium waves in rabbit articular chondrocytes and in HIG-82 synovial cells. J. Bone Miner. Res. 13, 443-453.

Grandolfo, M., D’Andrea, P., Martina, M., Ruzzier, F., and Vittur, F. (1992). Calcium-activated potassium channels in chondrocytes. Biochem. Biophys. Res. Commun. 182, 1429-1434.

Grandolfo, M., Martina, M., Ruzzier, F., and Vittur, F. (1990). A potassium channel in cultured chondrocytes. Calcif. Tissue Int. 47, 302-307.
Greig, E. R., Boot-Handford, R. P., Mani, V., and Sandle, G. I. (2004). Decreased expression of apical $\mathrm{Na}+$ channels and basolateral $\mathrm{Na}+, \mathrm{K}+$-ATPase in ulcerative colitis. J. Pathol. 204, 84-92.

Grishko, V., Xu, M., Wilson, G., and Pearsall, A. W. IV (2010). Apoptosis and mitochondrial dysfunction in human chondrocytes following exposure to lidocaine, bupivacaine, and ropivacaine. J. Bone Joint Surg. Am. 92, 609-618.

Gronemeier, M., Condie, A., Prosser, J., Steinmeyer, K., Jentsch, T. J., and Jockusch, H. (1994). Nonsense and missense mutations in the muscular chloride channel gene $\mathrm{ClC}-1$ of myotonic mice. J. Biol. Chem. 269, 5963-5967.

Guilak, F., Zell, R. A., Erickson, G. R., Grande, D. A., Rubin, C. T., McLeod, K. J., and Donahue, H. J. (1999). Mechanically induced calcium waves in articular chondrocytes are inhibited by gadolinium and amiloride. $J$. Orthop. Res. 17, 421-429.

Gutman, G. A., Chandy, K. G., Grissmer, S., Lazdunski, M., McKinnon, D., Pardo, L.A., Robertson, G. A., Rudy, B., Sanguinetti, M. C., Stuhmer, W., and Wang, X. (2005). International union of pharmacology. LIII. Nomenclature and molecular relationships of voltagegated potassium channels. Pharmacol. Rev. 57, 473-508.

Hall, A. C., Starks, I., Shoults, C. L., and Rashidbigi, S. (1996). Pathways for K+ transport across the bovine articular chondrocyte membrane and their sensitivity to cell volume. Am. J. Physiol. Cell Physiol. 270, C1300-C1310.

Hille, B. (2001). Ion Channels of Excitable Membranes. Sunderland, MA: Sinauer Associates.

Hodgkin, A. L., and Huxley, A. F. (1952a) The dual effect of membrane potential on sodium conductance in the giant axon of Loligo. J. Physiol. 116, 497-506.

Hodgkin, A. L., and Huxley, A. F. (1952b). A quantitative description of membrane current and its application to conduction and excitation in nerve. $J$. Physiol. (Lond.) 117, 500-544.

Iannotti, J. P. (1990). Growth plate physiology and pathology. Orthop. Clin. North Am. 21, 1-17.

Isoya, E., Toyoda, F., Imai, S., Okumura, N., Kumagai, K., Omatsu-Kanbe, M., Kubo,M., Matsuura, H., and Matsusue, Y. (2009). Swelling-activated Cl(-) current in isolated rabbit articular chondrocytes: inhibition by arachidonic acid. J. Pharmacol. Sci. 109, 293-304.

Jentsch, T. J., Steinmeyer, K., and Schwarz, G. (1990). Primary structure of Torpedo marmorata chloride channel isolated by expression cloning in Xenopus oocytes. Nature 348, 510-514.

Kerrigan, M. J. P., and Hall, A. C. (2008). Control of chondrocyte regulatory volume decrease (RVD) by [Ca2+] (i) and cell shape. Osteoarthr. Cartil. 16, 312-322.

Knight, M. M., McGlashan, S. R., Garcia, M., Jensen, C. G., and Poole, C. A. (2009).Articular chondrocytes express connexin 43 hemichannels and P2 receptors - a putative mechanoreceptor complex involving the primary cilium? J. Anat. 214, 275-283.

Kolker, S. J., Walder, R. Y., Usachev, Y., Hillman, J., Boyle, D. L., Firestein, G. S., and Sluka, K. A. (2010). Acid-sensing ion channel 3 expressed in type B synoviocytes and chondrocytes modulates hyaluronan expression and release. Ann. Rheum. Dis. 69, 903-909.

Krause, E., Englert, H., and Gogelein, H. (1995). Adenosine triphosphatedependent $\mathrm{K}$ currents activated by metabolic inhibition in rat ventricular myocytes differ from those elicited by the channel opener rilmakalim. Pflugers Arch. 429, 625-635.

Latorre, R., Oberhauser, A., Labarca, P., and Alvarez, O. (1989). Varieties of calcium-activated potassium channels. Annu. Rev. Physiol. 51, 385-399.

Ledoux, J., Werner, M. E., Brayden, J. E., and Nelson, M. T. (2006). Calciumactivated potassium channels and the regulation of vascular tone. Physiology 21, 69-78.

Lee, H. S., Millward-Sadler, S. J., Wright, M. O., Nuki, G., and Salter, D. M. (2000). Integrin and mechanosensitive ion channel-dependent tyrosine phosphorylation of focal adhesion proteins and beta-catenin in human articular chondrocytes after mechanical stimulation. J. Bone Miner. Res. 15, 1501-1509.

Lee, R. B., and Urban, J.P. (1997). Evidence for a negative Pasteur effect in articular cartilage. Biochem. J. 321(Pt 1), 95-102.

Lefevre, T., Lefevre, I.A., Coulombe,A., and Coraboeuf, E. (1996). Effects of chloride ion substitutes and chloride channel blockers on the transient outward current in rat ventricular myocytes. Biochim. Biophys. Acta. 1273, 31-43.

Lewis, R., Mobasheri, A., and BarrettJolley, R. (2008). Electrophysiological identification of epithelial sodium channels in canine articular chondrocytes. Proc. Physiol. Soc. 11, C47.

Lewis, R., Purves, G., Crossley, J., and Barrett-Jolley, R. (2010). Modelling the Membrane potential dependence on non-specific cation channels in canine articular chondrocytes. Biophys. J. 98. (Suppl. 1), 340A

Liang, H., Yang, L., Ma, T., and Zhao, Y. (2010). Functional expression of cystic 
fibrosis transmembrane conductance regulator in mouse chondrocytes. Clin. Exp. Pharmacol. Physiol. 37, 506-508.

Liang, H. T., Feng, X. C., and Ma, T. H. (2008). Water channel activity of plasma membrane affects chondrocyte migration and adhesion. Clin. Exp. Pharmacol. Physiol. 35, 7-10.

Lindemann, B. (2001). Receptors and transduction in taste. Nature 413, 219-225.

Lippiat, J. D., Standen, N. B., Harrow, I. D., Phillips, S. C., and Davies, N. W. (2003). Properties of BK(Ca) channels formed by bicistronic expression of hSloalpha and beta1-4 subunits in HEK293 cells. J. Membr. Biol. 192, 141-148.

Long, K. J., and Walsh, K. B. (1994). Calcium-activated potassium channel in growth-plate chondrocytes-regulation by protein-kinase-A. Biochem. Biophys. Res. Commun. 201, 776-781.

Mall, M., Bleich, M., Greger, R., Schreiber, R., and Kunzelmann, K. (1998). The amiloride-inhibitable $\mathrm{Na}+$ conductance is reduced by the cystic fibrosis transmembrane conductance regulator in normal but not in cystic fibrosis airways. J. Clin. Invest. 102, 15-21.

Mancilla, E. E., Galindo, M., Fertilio, B., Herrera, M., Salas, K., Gatica, H., and Goecke, A. (2007). L-type calcium channels in growth plate chondrocytes participate in endochondral ossification. J. Cell Biochem. 101, 389-398.

Mankin, H. J. (1982). The response of articular cartilage to mechanical injury. J. Bone Joint Surg. Am. 64, 460-466.

Mano, I., and Driscoll, M. (1999). DEG/ $\mathrm{ENaC}$ channels: a touchy superfamily that watches its salt. Bioessays 21, 568-578.

Martin, J.A., and Buckwalter, J. A. (2000). The role of chondrocyte-matrix interactions in maintaining and repairing articular cartilage. Biorheology 37, 129-140.

Martina, M., Mozrzymas, J.W., and Vittur, F. (1997). Membrane stretch activates a potassium channel in pig articular chondrocytes. Biochim. Biophys. Acta Biomembr. 1329, 205-210.

May, H., Mobasheri, A., Womack, M. D., and Barrett-Jolley, R. (2007). Functional expression of aquaporins in canine chondrocytes. Biophys. J. 92, S543.

McCarty, M. F. (1999). Endothelial membrane potential regulates production of both nitric oxide and superoxide - a fundamental determinant of vascular health. Med. Hypotheses. 53, 277-289.

Millward-Sadler, S. J., Wright, M. O., and Salter, D. M. (2001). The NMDA receptor is involved in the response of normal human articular chondrocytes to mechanical stimulation. J. Pathol. 193, 32a-32a.

Minami, K., Miki, T., Kadowaki, T., and Seino, S. (2004). Roles of ATP-sensitive $\mathrm{K}+$ channels as metabolic sensors: studies of Kir6.x null mice. Diabetes 53(Suppl. 3), S176-S180.

Mobasheri, A., Carter, S. D., MartinVasallo, P., and Shakibaei, M. (2002). Integrins and stretch activated ion channels; putative components of functional cell surface mechanoreceptors in articular chondrocytes. Cell. Biol. Int. 26, 1-18.

Mobasheri, A., Gent, T. C., Nash, A. I., Womack, M. D., Moskaluk, C. A., and Barrett-Jolley, R. (2007). Evidence for functional ATP-sensitive (K(ATP)) potassium channels in human and equine articular chondrocytes. Osteoarthr. Cartil. 15, 1-8.

Mobasheri, A., Gent, T. C., Womack, M. D., Carter, S. D., Clegg, P. D., and Barrett-Jolley, R. (2005a). Quantitative analysis of voltage-gated potassium currents from primary equine (Equus caballus) and elephant (Loxodonta africana) articular chondrocytes. Am. J. Physiol. Regul. Integr. Comp. Physiol. 289, R172-R180.

Mobasheri,A., Richardson, S., Mobasheri, R., Shakibaei, M., and Hoyland, J. A. (2005b). Hypoxia inducible factor-1 and facilitative glucose transporters GLUT1 and GLUT3: putative molecular components of the oxygen and glucose sensing apparatus in articular chondrocytes. Histol. Histopathol. 20, 1327-1338.

Mobasheri, A., Lewis, R., Maxwell, J. E. J., Hill, C., Womack, M., and BarrettJolley, R. (2010). Characterization of a stretch-activated potassium channel in chondrocytes. J. Cell. Physiol. 223, 511-518.

Mobasheri, A., and Marples, D. (2004). Expression of the AQP-1 water channel in normal human tissues: a semiquantitative study using tissue microarray technology. Am. J. Physiol. Cell Physiol. 286, C529-C537.

Mobasheri, A., Shakibaei, M., and Marples, D. (2004a). Immunohistochemical localization of aquaporin 10 in the apical membranes of the human ileum: a potential pathway for luminal water and small solute absorption. Histochem. Cell Biol. 121, 463-471.

Mobasheri, A., Trujillo, E., Bell, S., Carter, S. D., Clegg, P. D., Martin-Vasallo, P., and Marples, D. (2004b). Aquaporin water channels $\mathrm{AQP1}$ and $\mathrm{AQP} 3$, are expressed in equine articular chondrocytes. Vet. J. 168, 143-150.

Mouw, J. K., Imler, S. M., and Levenston, M. E. (2007). Ion-channel regulation of chondrocyte matrix synthesis in $3 \mathrm{D}$ culture under static and dynamic compression. Biomech. Model. Mechanobiol. 6, 33-41.

Mozrzymas, J. W., Martina, M., and Ruzzier, F. (1997). A large-conductance voltage-dependent potassium channel in cultured pig articular chondrocytes. Pflugers Arch. Eur. J. Physiol. 433, 413-427.

Muramatsu, S., Wakabayashi, M., Ohno, T., Amano, K., Ooishi, R., Sugahara, T., Shiojiri, S., Tashiro, K., Suzuki, Y., Nishimura, R., Kuhara, S., Sugano, S., Yoneda, T., and Matsuda, A. (2007). Functional gene screening system identified TRPV4 as a regulator of chondrogenic differentiation. J. Biol. Chem. 282, 32158-32167.

Neher, E., and Sakmann, B. (1992). The patch clamp technique. Sci. Am. 266 44-51.

Nilius, B., and Droogmans, G. (2003). Amazing Chloride Channels: An Overview, Oxford, UK: Blackwell Science Ltd, 119-147.

Nilius, B., Vriens, J., Prenen, J., Droogmans, G., and Voets, T. (2004). TRPV4 calcium entry channel: a paradigm for gating diversity. Am. J. Physiol. Cell Physiol. 286, C195-C205.

Otte, P. (1991). Basic cell metabolism of articular cartilage. Manometric studies. Z. Rheumatol. 50, 304-312.

Pallotta, B. S., and Wagoner, P. K. (1992). Voltage-dependent potassium channels since Hodgkin and Huxley. Physiol. Rev. 72, S49-S67.

Park, J. K., Kim, Y. C., Sim, J. H., Choi, M. Y., Choi, W., Hwang, K. K., Cho, M. C., Kim, K. W., Lim, S. W., and Lee, S. J. (2007). Regulation of membrane excitability by intracellular $\mathrm{pH}(\mathrm{pH}(\mathrm{i}))$ changers through $\mathrm{Ca} 2+$-activated $\mathrm{K}+$ current (BK channel) in single smooth muscle cells from rabbit basilar artery. Pflugers Arch. Eur. J. Physiol. 454, 307-319.

Penyige, A., Matko, J., Deak, E., Bodnar, A. and Barabas, G. (2002). Depolarization of the membrane potential by betalactams as a signal to induce autolysis. Biochem. Biophys. Res. Commun. 290, 1169-1175.

Pesente, L., and Signorile, G. (1979). [Effect of SITS (4-acetamido-4'-isothiocyanatostilbene-2,2'-disulfonic acid) on the transport of chloride through the isolated skin of Rana esculenta]. Ateneo Parmense Acta Biomed. 50, 173-179.

Phan, M. N., Leddy, H. A., Votta, B. J., Kumar, S., Levy, D. S., Lipshutz, D. B., Lee, S. H., Liedtke, W., and Guilak, F. (2009). Functional characterization of TRPV4 as an osmotically sensitive ion channel in porcine articular chondrocytes. Arthritis Rheum. 60, 3028-3037.
Phillis, J. W. (2004). Adenosine and adenine nucleotides as regulators of cerebral blood flow: roles of acidosis, cell swelling, and KATP channels. Crit. Rev. Neurobiol 16, 237-270.

Poiraudeau, S., Lieberherr, M., Kergosie, N., and Corvol, M. T. (1997). Different mechanisms are involved in intracellular calcium increase by insulin-like growth factors 1 and 2 in articular chondrocytes: voltage-gated calcium channels, and/or phospholipase C coupled to a pertussis-sensitive G-protein. J. Cell. Biochem. 64, 414-422.

Ponce, A. (2006). Expression of voltage dependent potassium currents in freshly dissociated rat articular chondrocytes. Cell. Physiol. Biochem. 18, 35-46.

Preston, G. M., Carroll, T. P., Guggino, W. B., and Agre, P. (1992). Appearance of water channels in Xenopus oocytes expressing red cell CHIP28 protein. Science 256, 385-387.

Quayle, J.M., Nelson, M. T., and Standen, N. B. (1997). ATP-sensitive and inwardly rectifying potassium channels in smooth muscle. Physiol. Rev. 77, 1165-1232.

Ramage, L., Martel, M. A., Hardingham, G. E., and Salter, D. M. (2008). NMDA receptor expression and activity in osteoarthritic human articular chondrocytes. Osteoarthr. Cartil. 16, 1576-1584.

Redini, F. (2001). Structure and regulation of articular cartilage proteoglycan expression. Pathol. Biol. (Paris) 49, 364-375.

Rhodes, T. H., Vite, C. H., Giger, U., Patterson, D. F., Fahlke, C., and George, A. L. Jr (1999). A missense mutation in canine $\mathrm{C} 1 \mathrm{C}-1$ causes recessive myotonia congenita in the dog. FEBS Lett. 456, 54-58.

Rojek, A., Praetorius, J., Frokiaer, J., Nielsen, S., and Fenton, R. A. (2008). A current view of the mammalian aquaglyceroporins. Annu. Rev. Physiol. 70, 301-327.

Rossier, B. C., Pradervand, S., Schild, L., and Hummler, E. (2002). Epithelial sodium channel and the control of sodium balance: interaction between genetic and environmental factors. Annu. Rev. Physiol. 64, 877-897.

Salkoff, L., Butler, A., Ferreira, G., Santi, C., and Wei, A. (2006). Highconductance potassium channels of the SLO family. Nat. Rev. Neurosci. 7, 921-931.

Salter,D. M., Wright, M. O., and MillwardSadler, S. J. (2004). NMDA receptor expression and roles in human articular chondrocyte mechanotransduction. Biorheology 41, 273-281.

Sampson, L. J., Davies, L. M., BarrettJolley, R., Standen, N. B., and Dart C. (2007). Angiotensin II-activated 
protein kinase $\mathrm{C}$ targets caveolae to inhibit aortic ATP-sensitive potassium channels. Cardiovasc. Res. 76, 61-70.

Sanchez, J. C., Danks, T. A., and Wilkins, R. J. (2003). Mechanisms involved in the increase in intracellular calcium following hypotonic shock in bovine articular chondrocytes. Gen. Physiol. Biophys. 22, 487-500.

Sanchez, J. C., Powell, T., Staines, H. M., and Wilkins, R. J. (2006). Electrophysiological demonstration of voltage-activated $\mathrm{H}+$ channels in bovine articular chondrocytes. Cell. Physiol. Biochem. 18, 85-90.

Sanchez, J. C., and Wilkins, R. J. (2004). Changes in intracellular calcium concentration in response to hypertonicity in bovine articular chondrocytes. Comp. Biochem. Physiol. A Mol. Integr. Physiol. 137, 173-182.

Shakibaei, M., and Mobasheri, A. (2003). Betal-integrins co-localize with $\mathrm{Na}$, K-ATPase, epithelial sodium channels $(\mathrm{ENaC})$ and voltage activated calcium channels (VACC) in mechanoreceptor complexes of mouse limb-bud chondrocytes. Histol. Histopathol. 18, 343-351.

Shakibaei, M., Schulze-Tanzil, G., de Souza, P., John, T., Rahmanzadeh, M., Rahmanzadeh, R., and Merker, H. J. (2001). Inhibition of mitogenactivated protein kinase kinase induces apoptosis of human chondrocytes. J. Biol. Chem. 276, 13289-13294.

Smith, B. L., and Agre, P. (1991). Erythrocyte Mr 28,000 transmembrane protein exists as a multisubunit oligomer similar to channel proteins. $J$. Biol. Chem. 266, 6407-6415.

Snyder, P. M., Price, M. P., McDonald, F. J., Adams, C. M, Volk, K. A., Zeiher, B. G., Stokes, J. B., and Welsh, M. J. (1995). Mechanism by which Liddle's syndrome mutations increase activity of a human epithelial $\mathrm{Na}+$ channel. Cell 83, 969-978.

Standen, N. B., and Stanfield, P. R. (1978). A potential- and time-dependent blockade of inward rectification in frog skeletal muscle fibres by barium and strontium ions. J. Physiol. 280, 169-191.

Stockwell, R. A. (1975). Structural and histochemical aspects of the pericellular environment in cartilage. Philos. Trans. R. Soc. Lond. B Biol. Sci. 271, 243-245.

Stutts, M. J., Canessa, C. M., Olsen, J. C., Hamrick, M., Cohn, J.A., Rossier, B.C., and Boucher, R. C. (1995). CFTR as a cAMP-dependent regulator of sodium channels. Science 269, 847-850.
Sugimoto, T., Yoshino, M., Nagao, M., Ishii, S., and Yabu, H. (1996). Voltagegated ionic channels in cultured rabbit articular chondrocytes. Comp. Biochem. Physiol. CPharmacol. Toxicol. Endocrinol. 115, 223-232.

Takahata, Y., Takarada, T., Osawa, M., Hinoi, E., Nakamura, Y., and Yoneda, Y. (2008). Differential regulation of cellular maturation in chondrocytes and osteoblasts by glycine. Cell Tissue Res. 333, 91-103.

Tatari, H. (2007). The structure, physiology, and biomechanics of articular cartilage: injury and repair. Acta. Orthop. Traumatol. Turc. 41(Suppl. 2), $1-5$.

Telezhkin, V.S., Tsvilovskii, V.V., Dyskina, Y. B., Davydovskaya, N. V., and Shuba, M. F. (2001). Effects of K+ channel blockers and nitric oxide on the electrical and contractile activities of smooth muscles of the rabbit main pulmonary artery. Neurophysiology 33, 281-288.

Tomai, F., Crea, F., Gaspardone, A., Versaci, F., De Paulis, R., Penta de Peppo, A., Chiariello, L., and Gioffre, P.A. (1994). Ischemic preconditioning during coronary angioplasty is prevented by glibenclamide, a selective ATP-sensitive $\mathrm{K}+$ channel blocker. Circulation 90, 700-705.

Torres, Y.P., Morera, F. J., Carvacho, I., and Latorre, R. (2007). A marriage of convenience: beta-subunits and voltagedependent K+ channels. J. Biol. Chem. 282, 24485-24489.

Trujillo, E., Alvarez de la Rosa, D., Mobasheri, A., Gonzalez, T., Canessa, C. M., and Martin-Vasallo, P. (1999). Sodium transport systems in human chondrocytes. II. Expression of ENaC, $\mathrm{Na}+/ \mathrm{K}+/ 2 \mathrm{Cl}-$ cotransporter and $\mathrm{Na}+/$ $\mathrm{H}+$ exchangers in healthy and arthritic chondrocytes. Histol. Histopathol. 14, 1023-1031.

Trujillo, E., Gonzalez, T., Marin, R., Martin-Vasallo, P., Marples, D., and Mobasheri, A. (2004). Human articular chondrocytes, synoviocytes and synovial microvessels express aquaporin water channels; upregulation of AQP1 in rheumatoid arthritis. Histol. Histopathol. 19, 435-444.

Tsuga, K., Tohse, N., Yoshino, M., Sugimoto, T., Yamashita, T., Ishii, S., and Yabu, H. (2002). Chloride conductance determining membrane potential of rabbit articular chondrocytes. J. Membr. Biol. 185, 75-81.

Urban, J. P. (1994). The chondrocyte: a cell under pressure. Br. J. Rheumatol. 33, 901-908.
Urban, J. P. G., Hall, A. C., and Gehl, K. A (1993). Regulation of matrix synthesis rates by the ionic and osmotic environment of articular chondrocytes. J. Cell. Physiol. 154, 262-270.

Vaca, L. (1999). SITS blockade induces multiple subconductance states in a large conductance chloride channel. J. Membr. Biol. 169, 65-73.

Villalonga, N., David, M., Bielanska, J., Vicente,R.,Comes,N.,Valenzuela,C., and Felipe,A. (2010). Immunomodulation of voltage-dependent $\mathrm{K}+$ channels in macrophages: molecular and biophysical consequences. J. Gen. Physiol. 135, 135-147.

Walsh, K. B., Cannon, S. D., and Wuthier, R. E. (1992). Characterization of a delayed rectifier potassium current in chicken growth plate chondrocytes. Am. J. Physiol. 262, C1335-C1340.

Wang, L. G., and Sigworth, F. J. (2009). Structure of the BK potassium channel in a lipid membrane from electron cryomicroscopy. Nature 461, 292-296.

Wemmie, J.A., Price, M. P., and Welsh, M. J. (2006). Acid-sensing ion channels: advances, questions and therapeutic opportunities. Trends Neurosci. 29, 578-586.

Wilkins, R. J., Browning, J.A., and Ellory, J. C. (2000). Surviving in a matrix: membrane transport in articular chondrocytes. J. Membr. Biol. 177, 95-108.

Wilson, J. R., Duncan, N. A., Giles, W. R., and Clark, R. B. (2004). A voltagedependent $\mathrm{K}+$ current contributes to membrane potential of acutely isolated canine articular chondrocytes. $J$. Physiol. (Lond.) 557, 93-104.

Wohlrab, D., Vocke, M., Klapperstuck, T., and Hein, W. (2004). Effects of potassium and anion channel blockers on the cellular response of human osteoarthritic chondrocytes. J. Orthop. Sci. 9, 364-371.

Wohlrab, D., Vocke, M., Klapperstuck, T., and Hein, W. (2005). The influence of lidocaine and verapamil on the proliferation, CD44 expression and apoptosis behavior of human chondrocytes. Int. J. Mol. Med. 16, 149-157.

Wohlrab, D., Wohlrab, J., Reichel, H., and Hein, W. (2001). Is the proliferation of human chondrocytes regulated by ionic channels? J. Orthop. Sci. 6 , 155-159.

Wright, M., Jobanputra, P., Bavington, C., Salter, D. M., and Nuki, G. (1996). Effects of intermittent pressureinduced strain on the electrophysiology of cultured human chondrocytes: evidence for the presence of stretch- activated membrane ion channels. Clin. Sci. 90, 61-71.

Wright, M. O., Stockwell, R. A., and Nuki, G. (1992). Response of plasma membrane to pplied hydrostatic pressure in chondrocytes and fibroblasts. Connect. Tissue Res. 28, 49-70.

Wu, M. H., Urban, J. P., Cui, Z. F., Cui, Z., and Xu, X. (2007). Effect of extracellular ph on matrix synthesis by chondrocytes in 3D agarose gel. Biotechnol. Prog. 23, 430-434.

Wu, Q. Q., and Chen, Q. (2000). Mechanoregulation of chondrocyte proliferation, maturation, and hypertrophy: ion-channel dependent transduction of matrix deformation signals. Exp. Cell. Res. 256, 383-391.

Xu, J., Wang, W., Clark, C. C., and Brighton, C. T. (2009). Signal transduction in electrically stimulated articular chondrocytes involves translocation of extracellular calcium through voltagegated channels. Osteoarthr. Cartil. 17, 397-405.

Yellowley, C. E., Hancox, J. C., and Donahue, H. J. (2002). Effects of cell swelling on intracellular calcium and membrane currents in bovine articular chondrocytes. J. Cell. Biochem. 86, 290-301.

Yuan, F. L., Chen, F. H., Lu, W. G., Li, X., Wu, F. R., Li, J. P., Li, C. W., Wang, Y., Zhang, T. Y., and Hu, W. (2010). Acid-sensing ion channel la mediates acid-induced increases in intracellular calcium in rat articular chondrocytes. Mol. Cell. Biochem. 340, 153-159.

Conflict of Interest Statement: The authors declare that the research was conducted in the absence of any commercial or financial relationships that could be construed as a potential conflict of interest.

Received: 07 July 2010; accepted: 09 September 2010; published online: 14 October 2010.

Citation: Barrett-Jolley $R$, Lewis R, Fallman $R$ and Mobasheri A (2010) The emerging chondrocyte channelome. Front. Physio. 1:135. doi: 10.3389/fphys.2010.00135

This article was submitted to Frontiers in Membrane Physiology and Biophysics, a specialty of Frontiers in Physiology. Copyright (C) 2010 Barrett-Jolley, Lewis, Fallman and Mobasheri. This is an openaccess article subject to an exclusive license agreement between the authors and the Frontiers Research Foundation, which permits unrestricted use, distribution, and reproduction in any medium, provided the original authors and source are credited. 